\title{
On the Chromosome Morphology of Certain Pisces
}

\author{
By \\ Alexandra Prokofieva \\ The Laboratory of Genetics, Academy of Sciences \\ of U.S.S.R., Leningrad
}

Received Jantary 17,1934

Among the Vertebrate the fish class is the least studied cytologically. Most of the investigations carried out in this domain relate to the end of the last and the beginning of the present century and represent either general studies of the first phases of fertilized egg segmentation and embryo development (Opperman, 1913) or comprehensive descriptions of spermatogenesis and oogenesis processes with an approximate calculation of the number of chromosomes (Katstschenko, 1890; Ravitz, 1899; Schreiner, 1904; Rückert, 1892 etc.). Later on there appeared more circumstantial works indicating haploid and diploid numbers and analyzing the behaviour of the sexual chromosomes of some fish species: Lebistes reticulatus, $2 \mathrm{n}=46$ (Winge, 1922, 1923); Oryzias latipes, $2 \mathrm{n}=48$ (Iriki, 1932); Umbra limi, $2 \mathrm{n}=22$ (Foley, 1926).

As to the domain of a more detailed investigation of chromesome sturcture there belong to it but the works of Agar (1911, '12, '13), treating of the structure of chromosomes in spermatogonial and somatic cells of Lepidosiren paradoxa (Dipnoe).

The problem to be solved in the present investigation is the examination of the chromosome structure of some fish species in the light of the principles recently established for the structure and evolution of chromosomes in plants (Levitsky, 1931).

\section{Material and Methods}

The materials of the present karyological study are our fishery fishes : Salmo salar L., Salmo fario L., Coregonus lavaretus baeri, and the hybrids of: Salmo salar $\times$ Salvelinus fontinalis, and Coregonus lavaretus baeri $\times$ Salvelinus fontinalis. Reproduction in each fish species 
studied takes place late in the Autumn, from the 15th of October till the 15th of December, at water temperatures averaging from $+3^{\circ}$ to $+6^{\circ} \mathrm{C}$. The investigation was carried out upon artificially fertilized roe, 5-10 days after fertilization. From the standpoint of technique, the treatment of the material offered some difficulties, as the embryo could not be isolated from the roe for fixation without destroying its cells. After a number of unsuccessful attempts at fixing the embryo separately, the roe had to be therefore, fixed wholly in a vessel the bottom of which had been covered with wadding. 24 hours after fixation the roe was transferred into distilled water, in which the preparation of the embryo from every roe globule took place with the help of a needle and pincers. Thus, only the embryos freed from roe were subjected to a following rinse in running water for 24 hours. The care with which the rinsing was carried out was doubtlessly one of the causes, owing to which struck together chromosomes were discovered in none of the objects investigated, whereas such cases were often observed when rinsing embryos together with roe. After rinsing, the material was treated with spiritus, xylol and paraffin in the usual way. Sections were made $10-15 \mu$ thick, depending on the segmentation stage, and stained with Heidenhain's ferric haematoxilin.

For the purpose of fixing, I mainly used a mixture of $5 \%$ chromic acid with $50 \%$ formalin at a ratio of " $5: 5$ " (Levitsky's liquid), which had served to differentiate the chromosomes of many plants with excellent effect.

With the roe of Salmo fario I also tested other mixtures (as formalin with picric acid, corrosive sublimate, chloric platinum), but the results proved worse in all of them : after applying these reagents, the external layer matrix substance became stainable, as well as the chromosome axis, the exposition of the morphological structure of the chromosome proving a failure.

\section{Special Part}

\section{Salmo salar L. (Figs. 1-3)}

The investigation has shown that the most propitious moment for the karyological analysis of the species is the one coinciding with the 6-8 day stage of the embryos. Although larger cells may be found at still earlier segmentation stages, the number of corresponding mitoses is small. At a period exceeding 8 days, segmentation stages 
give many mitoses, but the cells in such embryos are so very small, that the analysis of their chromosomes becomes difficult even for the calculation of their number, so much the more for revealing their morphological structure. An embryo from 6 to 8 days old possesses cells sufficiently large to enable an easy observation both of the number and morphology of its chromosomes. The mitoses number is at the same time large enough for the choice of suitable plates. In revealing the chromosome morphology of this species the best results were obtained after fixing with a strong mixture of chromic formalin (ratio $5: 5$ ). In spite of the large number of chromosomes resulting from this method of treatment, all of them lay disconnected in the protoplasma of large cells without displaying any tendency to stick together, as it
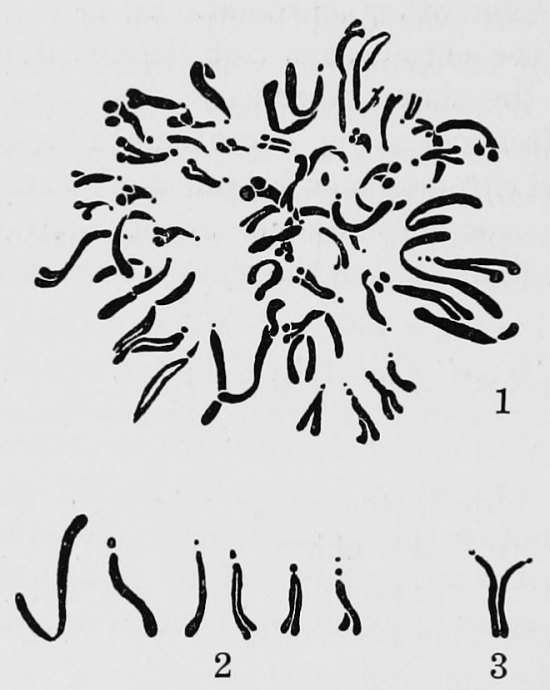

Figs. 1-3. Salmo salar L. $\times 1800.1$, Metaphase. 2, Structure of various chromosomes in metaphase. 3, Headed chromosome (anaphase). had been described by other investigators (Pinney, 1918; Moenkhaus, 1904 ; Behrens, 1909 and others).

The total number of chromosomes in the process of cell segmentation of Salmo salar L. is 60 (Fig. 1). Owing to the presence of a median, subterminal and terminal constriction, most of the chromosomes show a distinct differentiation into two arms.

Among the chromosomes there may be established 5 types: 1) long, equilateral chromosomes, 2) long, inequilateral chromosomes, 3) long, headed chromosomes, 4) small (short), headed chromosomes, 5) chromosome with satellites (one pair).

There are 4 pairs of long, equilateral chromosomes to a set in Salmo salar. They have a single median constriction, assuming the shape of a slight stricture in the chromosome body. These chromosomes yield to differentiation with the greatest difficulty. Long inequilateral chromosomes, i.e. chromosomes with one arm more or less shortened in comparison to the other, are the fewest in the set of Salmo salar, there are but 2 pairs of them. The subterminal constriction in these chromosomes is of a stricture 
shape in the chromosome body, similar to the one occurring in equilateral chromosomes.

Long headed chromosomes, i.e. chromosomes with an arm reduced to a minute head, are very numerous in the set of Salmo salar. They readily reveal differentiation, and their structure formed of a long arm and a small head may be easily perceived both when observing the metaphases "en face" and when investigating the spindle in profile. In some of the chromosomes the head is particularly perceptible, owing to the achromatic break, severing it from the long arm.

Small (short) headed chromosomes form the greater part of all the chromosomes of Salmo salar. The head may be distinctly seen in a number of chromosomes. As a rule it is turned to the inside of the plate. The head is separated from the long arm by a constriction assuming the shape both of a stricture and of an achromatic break.

The differentiation of a part of the chromosomes of Salmo salar has proved a failure. They are of the shape of the so-called "rod like" chromosomes, described as often occurring in various animal groups. I consider them to be headed chromosomes as well, their head having been apparently drawn into the chromosome, owing to the insufficiently rapid penetration of the fixative into the embryo through the roe film.

\section{Coregonus lavaretus baeri Kessler. (Figs. 4, 5)}

The most suitable moment for analysing the chromosome structure of the species has proved to be the five day stage of its embryo (Fig.4). Chromosome differentiation is achieved in this species with difficulty. Still many chromosomes have shown a more less distinct bi-armed structure on being fixed with a strong solution of chromic formalin (ratio-" $5: 5$ ").

The following preliminary groupings of the chromosomes of this species may be suggested:

1) Long, equilateral chromosomes -6 pairs. Three pairs of them are particularly conspicuous for their size. The median constriction of these chromosomes is of the shape of a slight stricture, perceptible in different chromosomes with varying distinctness.

2) Long, inequilateral chromosomes. The submedian constriction of these chromosomes (consisting of 2 pairs) assumes the form of a slight stricture, similar to the one in the preceding group.

3) Long, headed chromosomes. Contrary to Salmo salar chromosomes of this type in Coregonus baeri have no achromatic break 
between the long arm of the chromosome and the head. The head is more or less distinctly perceptible and is in every instance separated
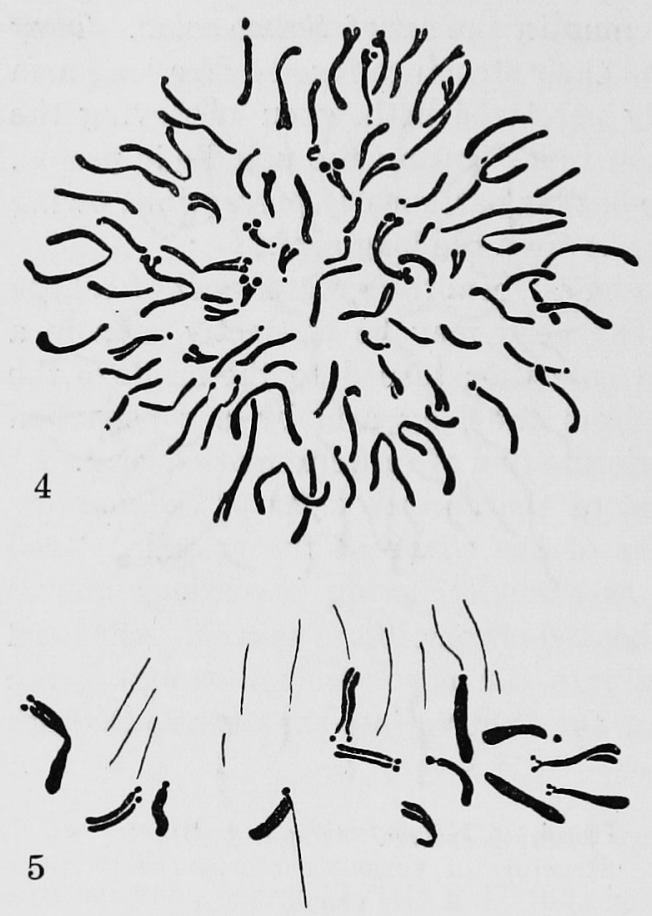

Figs. 4, 5. Coregonus baeri. $\times 1880.4$, Metaphase. 5, Metaphase. from the arm by a slight stricture.

4) Small (short), headed chromosomes, forming in Coregonus baeri, as in Salmo salar the majority of the chromosomes in the set. The head is more or less distinctly seen in different chromosomes; but it is, never separated from the long arm by an achromatic break. On fixing with the " $5: 5$ " solution, the morphological structure of a part of the chromosomes has remained unrevealed. Most of them appear to be small headed chromosomes.

The total somatic chromosome number of the species amounts to 80 . Both on fixing with chromic formalin (ratio-5:5), and on applying Navashin's liguid, the chromosomes lay separated from one another, so that their number could be calculated without any error.

\section{Salmo fario L. (Figs. 6, 7)}

As I had at my disposal a greater quantity of trout roe than that of the salmon and gwyinad, I was able to apply to this species a greater number of different fixatives. Namely, the fixatives tested were: different component ratios of strong and weak chromic formalin, ${ }^{1)}$ then mixtures of formalin with chloric platinum, corrosive sublimate, and picric acid. In spite of the method of treating the trout roe being identical with the one applied in the roe of Salmo salar and Coregonus

1) $10 \%$ formalin with $1 \%$ chromic acid and $50 \%$ formalin with $5 \%$ chromic acid. 
baeri, the chromosomes displayed a tendency to stick to one another under every fixative tested. The best results were, however, obtained after fixing with a compound of strong chromic formalin " 5:5". The total somatic number of chromosomes in Salmo fario equals 84 (see Fig. 6). Most of them have a more or less distinctly perceptible constriction of the shape of a stricture in the chromosomes body. After the length of the chromosomes and the position of the constriction in them, all the chromosomes of the species may be divided into 4 groups, just as the chromosomes of Salmo salar and Coregonus baeri. Namely:

1) Long, equilateral chromosomes.

2) Long, inequilateral chromosomes.

3) Long, headed chromosomes. somes.

4) Small, headed chromo-

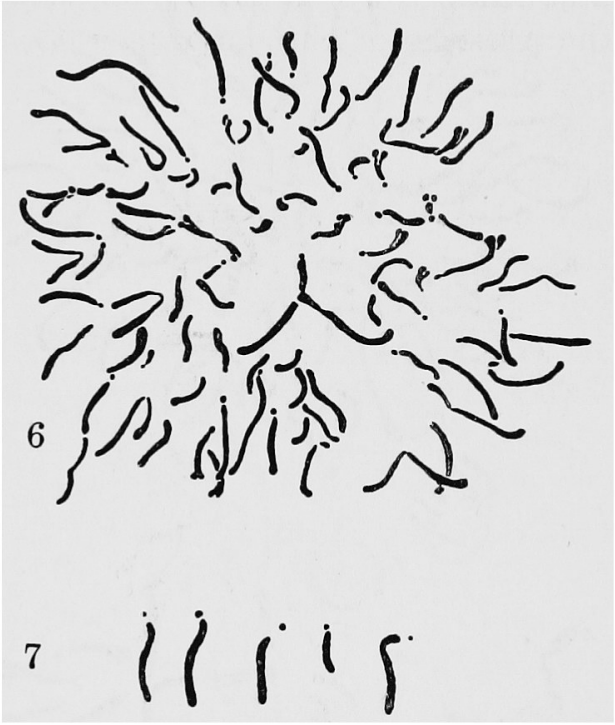

Figs. 6, 7. Salmo fario L. 6, Metaphase. 7, Structure of various chromosomes in metaphase.

In every instances the constriction assumes the shape of a stricture, sometimes rather pronounced.

\section{Hybrids (Figs. 8-12)}

Of all the fish hybrids studied the most interesting results have been obtained in analyzing the somatic plates of 8-day embryos of Salmo salar $\times$ Salvelinus fontinalis and Coregonus baeri $\times$ Salvelinus fontinalis hybrids.

I have not had a pure specimen of Salvelinus fontinalis Mitchi species at my disposal, nevertheless its chromosomes appear to differ in some respects from those of the species described above.

The Salmo salar $\times$ Salvelinus fortinalis hybrid has 70 chromosomes (Fig. 10), while the Coregonus baeri $\times$ Salvenlinus fontinalis hybrids contains 80 chromosomes in its cells (Fig. 8), from which the conclusion 
should be drawn that the diploid set of Salvelinus fontinalis equals 80 . Besides the 4 chromosome types discovered in the Coregonus baeri and Salmo fario these hybrids possesses in their sets markedly pronounced chromosomes with satellites as in the sets of Salmo salar. This is the first instance of a secondary chromosome differentiation in fishes, and the presence of chromosomes with satellites in the hybrid (Coregonus

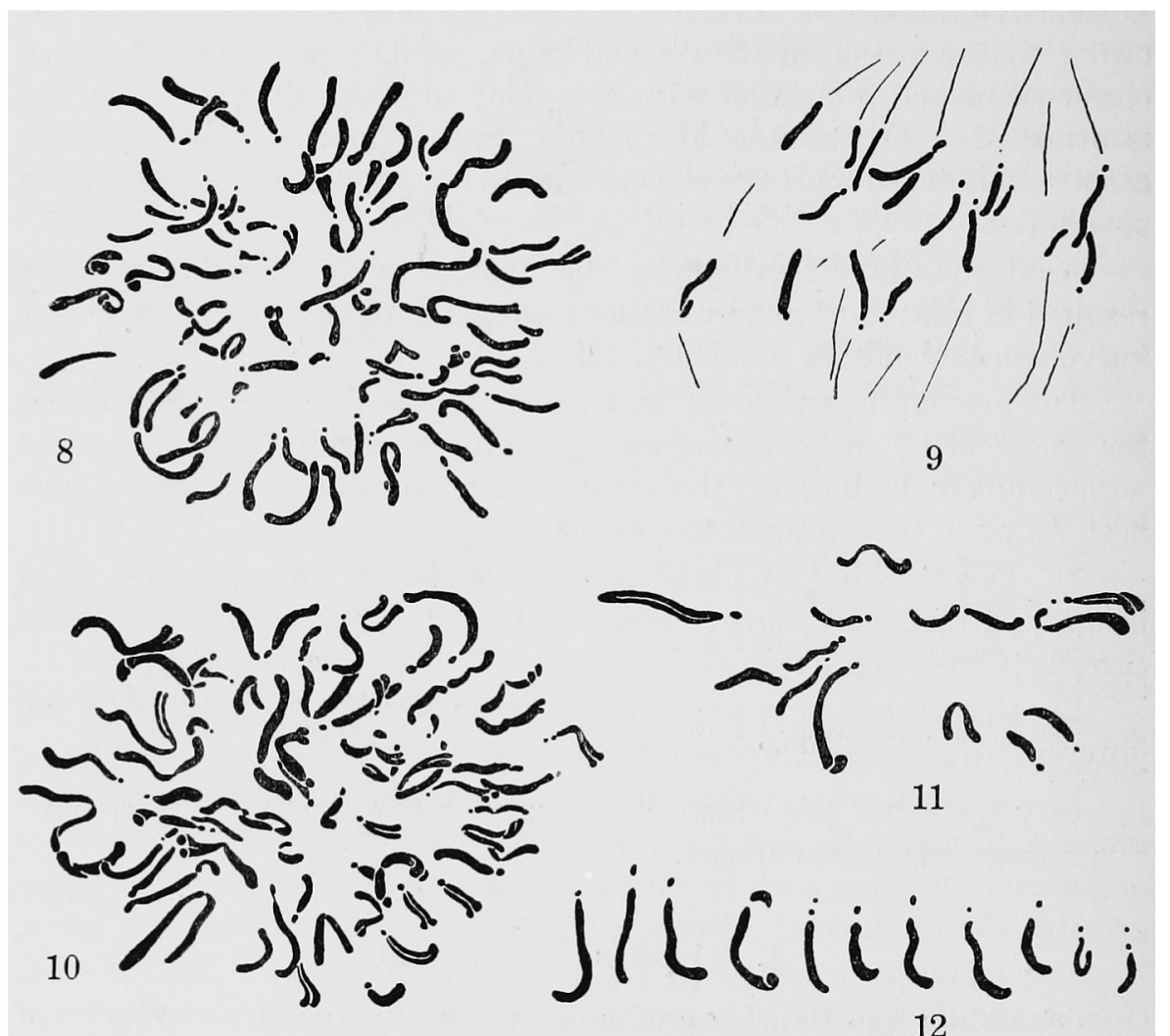

Figs. 8, 9. Coregonus baeri $\times$ Salvelinus fontinalis. $\times 1880$. 8, Metaphase. 9, Late anaphase. Figs. 10-12. Salmo salar $\times$ Salvelinus fontinalis. $\times 1880.10$, Metaphase. 11, Anaphase. 12, Structure of various chromosoes.

baeri $\times$ Salvelinus fontinalis) set compels us to refer them to the karyotype of Salvelinus fontinalis, as chromosomes of such a type have been found neither in Salmo fario, nor in Coregonus baeri. The sets of hybrids possess equilateral, inequilateral and headed chromosomes with a clearly perceptible constriction. It assumes the shape either of 
a more or less distinct stricture in the chromosome body or of an achromatic break, particularly perceptible in headed chromosomes. (Figs. 8-12).

\section{Discussion}

Agar (1911, 1912, 1913), when studying the chromosomes of Lepidosiren paradoxa, discovered their definite bilateral structure, owing to the presence of a constriction, strictly constant in every chromosome and coinciding with the point to which the spindle thread is attached. He was one of the first investigators to consider the constriction of chromosomes a constant and characteristic basis of their structures.

Analogous investigations in the domain of plant cytology have resulted in important generalizations enabling to reveal the course of karyological evolution (Levitsky, 1931).

The present investigation, carried out for the purpose of elucidating the question of the chromosome structure of certain fishes, revealed with complete distinctness the same basic maxims of structure, as have been found in the chromosomes of plants :

1) Bi-armedness of chromosomes caused by the presence of a primary attachment constriction at the point to which the spindle threads (fibres) are attached.

2) Occurrence of a secondary differentiation, resulting from the differentiation of the chromosome arms in the course of evolution.

In the fish species studied this process appears to result in chromosomes with markedly unequal arms, headed chromosomes and chromosomes with satellites, such chromosomes arising in consequence of a progressive shortening and differentiation of one of the chromosome arms.

The material investigated (by me) permits to mark but the basic (fundamental) features of resemblance in the karyological evolution of fishes and plants.

The treatment of this problem shall be the object of our further investigation.

\section{Summary}

1. The study of chromosome plates of 6-8 day embryos has given chromosome numbers: for Salmo salar $=60$, Coregonus lavaretus baer $i=$ 80 , Salmo fario $=84$, for Coregonus baeri $\times$ Salvelinus fontinalis hybrids $=$ 80 , and Salmo salar $\times$ Salvelinus fontinalis hybrids $=70$. 
2. The chromosomes of all the fishes investigated have clearly displyed a bilateral structure. After the position of the constriction and the length of chromosome arms, these chromosomes may be divided into 4 types: long, equilateral ones; long, inequilateral ones; long, headed ones; and small headed ones.

3. In the chromosome plates of Salmo salar and Salmo salar $\times$ Salvelinus fontinalis and Coregonus baeri $\times$ Salvelinus fontinalis hybrids there have been discovered chromosomes with satellites.

4. The chromosome structure of the studied fish species corresponds to the maxims of structure of chromosomes revealed in plants and gives grounds for supposing a course of karyological evolution common to both the animal and vegetable kingdom.

\section{Literature}

1. Agar, W.E. 1911. The Spermatogenesis of Lepicosiren paradoxa. Quart. Journ. Micr. Sc. Vol. LXII, pp. 1-44.

2. - 1912. Transverse Segmentation and Internal Differentiation of Chromosomes. Ibid. Vol. LVIII.

3. 1913. Transverse Segmentation and Internal Differentiation of Chromosomes. Ibid. Vol. LXIII.

4. Foley, Y. O. 1926. The Spermatogenesis of Umbra limi with Special Reference to Behaviour of the Spermatogonical Chromosomes and the First Maturation Division. Biol. Bull. Vol. I.

5. Geiser, S. W. 1924. Sex-Ratio and Spermatogenesis in the Topminnow Gambusia holbrook. Biol. Bull. Vol. XLVII.

6. Iriki, S. 1932. Studies on the Chromosomes of Pisces. On the Chromosomes of Aplocheilus latipes. Sc. Reports of the Tokyo Bunrika Daigaku. Sec. B. Vol. I.

7. Katstschenko, 1890. Uber den Reifungsprocess des Selachiereies. Zeitschr. wiss. Zool. Bd. L.

8. Levitsky, G. A. 1931. The Morphology of Chromosomes. Bull. of Appl. Bot. Vol. XXVII.

9. - 1931. The "Karyotype" in Systematics. Bull. of Appl. Bot. Vol. XXVII.

10. Oppermann, 1913. Die Entwicklung von Forelleneiern nach Befruchtung mit radiumbestrablten Samenfäden. Arch. mikr. Anat. Bd. LXXXIII.

11. Ravitz, 1899. Untersuchungen über Zellteilung. II. Die Teilung der Hodenzellen und die Spermatogenese bei Scyllium canicula. L. Arch. f. mikr. Anat. Bd. LIII.

12. Schreiner, 1904. Die Reifungsteilungen bei den Wirbeltieren. Ein Beitrag zur Frage nach der Chromatinreduktion. Anat. Anz. Bd. XXIV. 